\title{
Ceratoplastia com recobrimento de terceira pálpebra em felino doméstico para o tratamento de descemetocele com perfuração de córnea
}

\author{
Keratoplasty with Covering Third Eyelid in Domestic Feline for \\ Descemetocele Treatment with Corneal Perforation
}

\author{
Wandercleyson Uchôa Abreu' ${ }^{1}$ Caroline Philippsen ${ }^{2} \&$ Dennis José da Silva Lima ${ }^{3}$
}

\begin{abstract}
Background: Descemetocele is a lesion on the descemet's membrane most often caused by very deep ulcerations in the cornea, where the epithelium, basement membrane and stroma layers are exposed, leading to a distortion of the corneal structure. Because it is an injury whose evolution can lead to loss of vision, Descemetocele is considered a surgical emergency because, within the various techniques adopted, there is always an attempt to preserve the ocular bulb. Thus, the adoption of various reconstructive keratoplasty procedures have been described in descemet's membrane repair and ocular perforations of varying degrees of extension. In this surgical technique, tissue fragments (autogenous, autologous or xenologous) are usually used, the surgical method being defined according to the degree of injury (partial or total) and the amount of tissue required to be replaced. The aim of this study was to report a case of Keratoplasty with a third eyelid covering for descemetocele correction with corneal perforation in a domestic cat.

Case: A 2-year-old feline female was treated at the Veterinary Hospital of the University of Amazonia (UNAMA), presenting a traumatic ocular lesion with evolution of more than 25 days, refractory to treatment as eye drops. The ophthalmologic examination revealed presence of extravasated polymerized necrotic tissue in the cornea of the left eye, with Descemetocele as diagnosis. The treatment indicated was Reconstructive Keratoplasty without graft with third eyelid coating. As an anesthetic protocol, MPA was used with acepromazine, ketamine hydrochloride as the inducing agent and isoflurane in mask vaporization for the maintenance of the anesthetic plane. After preparation of the patient, the surgical procedure consisted of excision with a scalpel blade of the necrotic tissue, exposure of the endothelial layer and suture of the cornea with Vincry $1^{\circledR}$, in a simple discontinuous pattern. The third eyelid flap was then recovered by traction and fixation of the lesion in the direction of its movement, using the discontinuous (U-shaped) Wolf suture with Vincryl ${ }^{\circledR}$. For the postoperative period cephalexin $30.0 \mathrm{mg} \mathrm{kg}^{-1}$ BID was prescribed for 10 days and ketoprofen $2.0 \mathrm{mg} \mathrm{kg}^{-1} \mathrm{SID}$ was prescribed for 4 days and the use of Elizabethan collar was recommended. After 20 days, the animal returned and the corneal integrity returned. Discussion: Many inflammatory and infectious conditions can cause Descemetocele. In the case presented here, among these conditions, trauma with secondary bacterial infection, leading to chronic corneal ulceration was determinant for the appearance of this disease. The main therapeutic goal in these cases is to provide support from the Descemetocele area to prevent imminent leakage of the aqueous humor. Tissue adhesives, therapeutic contact lenses (TBCLs), membrane transplantation, among other techniques, have been reported for the treatment of this disease. In the case of the feline in question, the surgical therapy of Keratoplasty was adopted, a technique recommended for the correction of corneal damage. The coating with the third eyelid set in the Keratoplasty for Descemetocele correction was already described in cats andalso followed in the present study. Severe complications after surgical treatment of descemetocele with corneal perforation may occur, however, during the treatment instituted in the feline patient, the method was completely successful.
\end{abstract}

Keywords: keratoplasty, healing, descemet membrane.

Descritores: ceratoplastia, cicatrização, membrana de descemet. 


\section{INTRODUÇÃO}

A descemetocele é uma lesão na membrana de descemet decorrente de ulcerações muito profundas, onde as camadas corneanas como o epitélio, a membrana basal e o estroma são expostas. Esse tipo de lesão ocularleva a uma distorção da córnea, é por ser grave, deve ser considerada uma emergência cirúrgica,pois a intervenção para o tratamento deve ser imediata na tentativa de preservar o bulbo ocular [3].

A adoção de vários procedimentos cirúrgicos reconstrutivos tem sido descritos na reparação de descemetocele e perfurações oculares de vários graus de extensão [5]. As técnicas cirúrgicas de Ceratoplastia, geralmente utilizam fragmentos teciduais, que dependendo do tipo de tecido podem ser classificadas como autógenos (próprio indivíduo), autólogos (mesma espécie) ou xenólogos (outra espécie). Sendo que tal intervenção, é definida de acordo com a avaliação oftalmológica quanto ao grau da lesão (parcial ou total) e se a quantidade de tecido requerido a ser substituído encontra-se disponível [11].

Sendo pouco frequentes as enfermidades oftálmicas em animais domésticos onde se adotam manobras cirúrgicas com a finalidade de preservar o olho, objetivou-se relatar um caso de Ceratoplastia com recobrimento de terceira pálpebra, para correção de descemetocele com perfuração corneana em um felino doméstico.

\section{CASO}

Foi atendido um felino, SRD (sem raça definida), fêmea, de 2 anos de idade no Hospital Veterinário da Universidade da Amazônia - HOVET/UNAMA, com histórico clínico de lesão ocular traumática (olho esquerdo) com evolução de mais de 25 dias e refratária a terapia farmacológica com colírios. Ao exame oftálmico observaram-se: hiperemia e edema de conjuntiva, lesão extensa corneana de localização canto-medial com extravasamento de conteúdo amarelado, polimerizado e de aspecto necrótico (Figura 1), sensibilidade dolorosa, PIO (pressão intraocular) normal, edema de córnea peri-lesional, neovascularização estromal profunda e blefaroespasmo. O teste de Seidel, demostrou a presença de humor aquoso extravasando do local da lesão junto a Fluoresceína, denotando perfuração da membrana córnea.

Diante dos achados clínico e histórico, o diagnóstico foi dedescemetocele, ocasionada por úlcera de córnea profunda com complicação bacteriana. $\mathrm{O}$ trata-

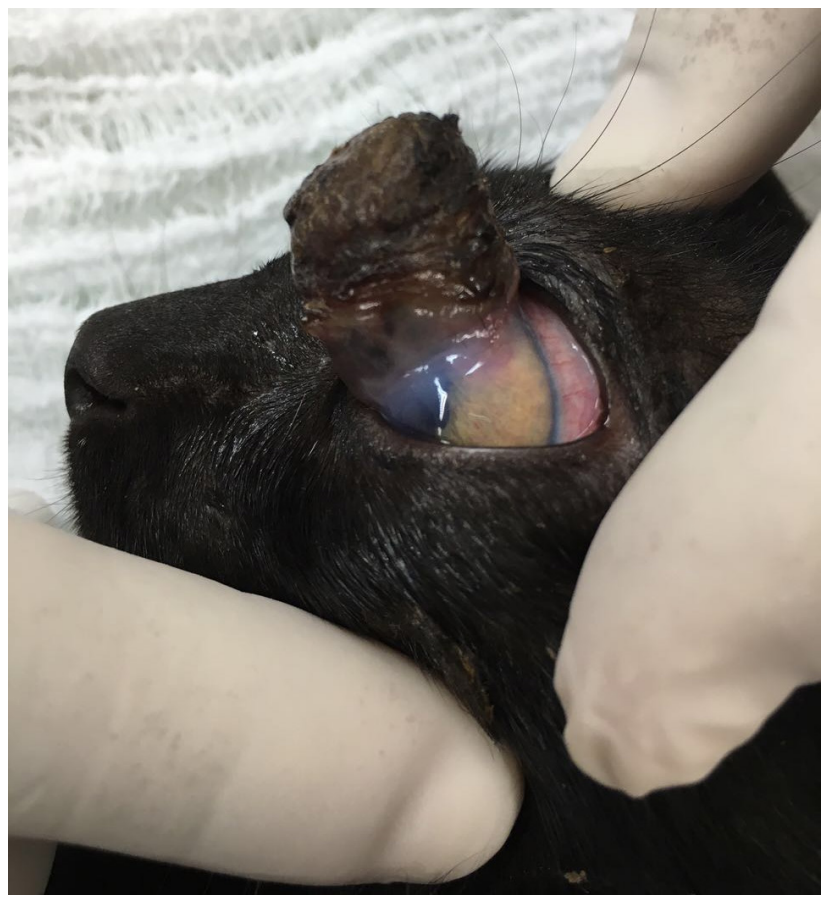

Figura 1. Lesão de córnea do olho esquerdo apresentando dano extenso e conteúdo de característica necrótica e de infecção bacteriana.

mento indicado foi a Ceratoplastia Reconstrutiva sem uso de enxerto, com recobrimento de terceira pálpebra.

$\mathrm{O}$ animal foi submetido aos exames pré-operatórios, apresentando os valores hematológicos e de bioquímicas séricas dentro daqueles preconizados para a espécie. O protocolo anestésico seguiu-se de: MPA (medicação pré-anestésica): acepromazina $4.0 \mathrm{mg} \mathrm{kg}^{-1}$ $\left(\text { Apromazin }^{\circledR}\right)^{1}$; Indução anestésica: cloridrato de ketamina $10.0 \mathrm{mg} \mathrm{kg}^{-1}\left(\text { Cetamin }^{\circledR}\right)^{1}$ e a manutenção do plano anestésico: isoflurano (Isoflurane $\left.{ }^{\circledR}\right)^{2} \mathrm{em}$ vaporização em máscara inalatória com $100 \%$ de oxigênio. O animal foi mantido em fluidoterapia em gotejamento lento com solução fisiológica $0,9 \%$ (Cloreto de sódio $\left.0,9 \%{ }^{\circledR}\right)^{3}$ durante todo o ato cirúrgico.

Após anestesiado, o animal foi posicionado em decúbito lateral contrário ao olho afetado, em seguida realizou-se a tricotomia periocular, limpeza com solução fisiológica a $0,9 \%$ estéril (Cloreto de sódio $\left.0,9 \%{ }^{\circledR}\right)^{3} \mathrm{e}$ algodão, delimitação do campo operatório e gotejamento de tobramicina oftálmica a $0,03 \%\left(\text { Tobrex }^{\circledR}\right)^{4}$ como antibioticoterapia profilática no globo ocular a ser operado.

O trans-operatório seguiu-se da excisão com bisturi (lâmina $\left.\mathrm{n}^{\circ} 15\right)$, , contornando a lesão para a retirada do tecido necrosado e revascularização dos bordos por debridamento (Figura 2). Em seguida, realizou-se a exposição da camada endotelial da córnea e realização da ceratorrafia com sutura descontinua simples com fio de poliglactina $4.0\left(\text { Vincryl }^{\circledR}\right)^{5}$. 


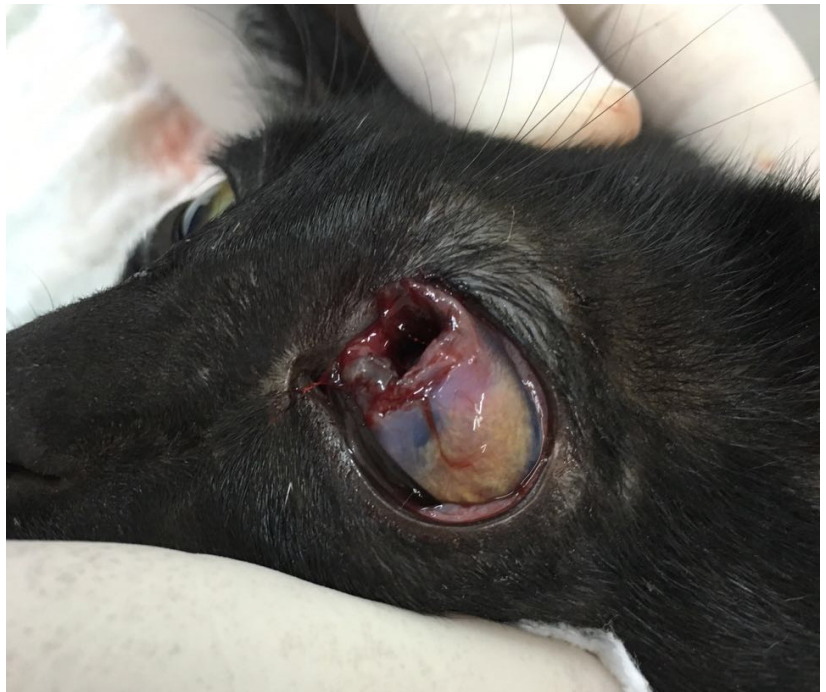

Figura 2. Retirada de tecido necrosado.

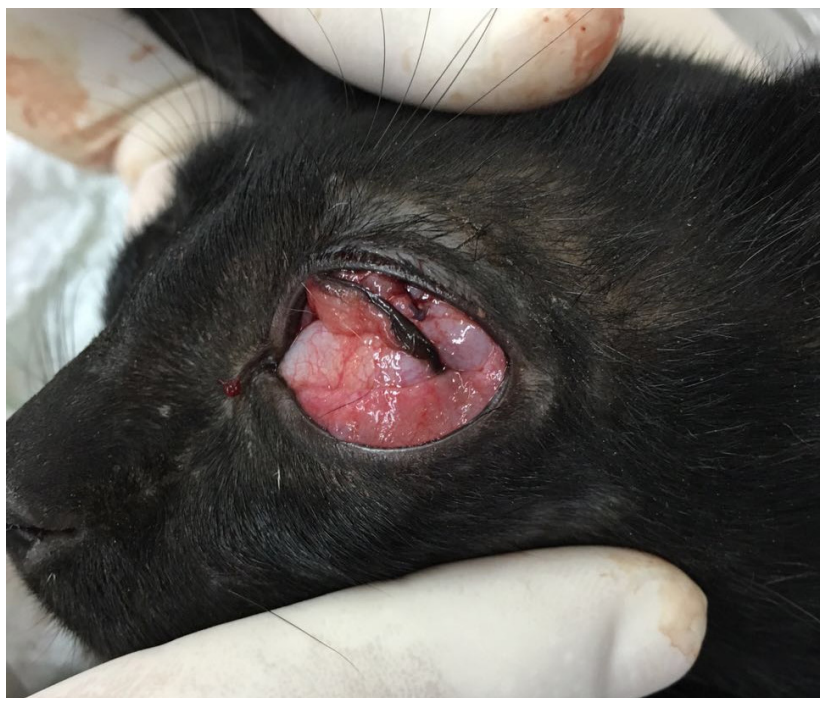

Figura 3. Recobrimento da lesão com a de terceira pálpebra.

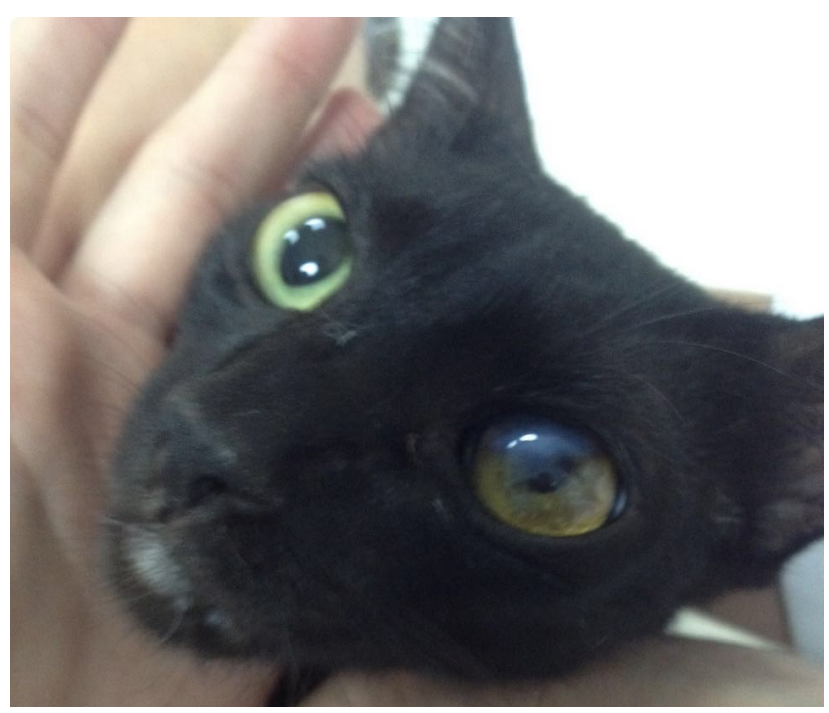

Figura 4. Resultado do olho operado após 20 dias da Ceratoplastia.
Após a oclusão da perfuração, realizou-se a limpeza com solução fisiológica estéril e recobriu-se a mesma com a terceira pálpebra. Para tal manobra, utilizou-se o fio de poliglactina $2.0\left(\text { Vincryl }^{\circledR}\right)^{5}$ para posicionar as suturas de Wolf descontinuas (em U), que foram feitas transpassando a cartilagem da terceira pálpebra e suturadas a 2 mm da margem da pálpebra superior. A tração da sutura foi feita na direção de movimentação da terceira pálpebra, utilizando-se 3 pontos (Figura 3).

Para o pós-operatório foram prescritos cefalexina $30.0 \mathrm{mg} \mathrm{kg}^{-1} \mathrm{BID}\left(\text { Rilexine }^{\circledR}\right)^{6}$ por 10 dias e cetoprofeno $2.0 \mathrm{mg} \mathrm{kg}^{-1} \mathrm{SID}\left(\operatorname{Ketofen}^{\circledR}\right)^{7}$ por 4 dias. Recomendou-se o uso de colar Elisabetano.

Após 20 dias o animal retornou para avaliação, a descemetocele já havia regredido, bem como a úlcera de córnea, restando apenas uma "mancha" cicatricial (Figura 4).

\section{DISCUSSÃO}

A descemetocele, hérnia ou abaulamento anterior da membrana de descemet é uma rara, mas importante condição ocular que pode facilmente evoluir para a perfuração total da córnea. Muitas condições inflamatórias e infecciosas, tais como infecções bacterianas, fúngicas, virais, ceratite, doença vascular e de colágeno, ceratopatia de exposição, úlceras de córnea neurotrófiticas edegeneração da córnea e/ectasia, podem causar descemetocele [7,9]. Dentre tais condições, no presente relato foi observado que a causa principal foi o trauma com infeccção bacteriana secundária, levando a ulceração crônica da córnea e suas camadas.

A principal meta terapêutica é fornecer apoio da área de descemetocele para evitar iminenteextravazamento do humor aquoso. Adesivos teciduais, lentes de contatoterapêuticas (TBCLs), transplante de membrana, dentre outras técnicas, tem sido relatadas para o tratamento desta enfermidade [6,7]. No felino em questão, adotou-se a terapia cirúrgica de Ceratoplastia, uma técnica preconizada para a correção de danos na membrana córnica.

Em oftalmologia veterinária o uso de submucosa acelular do próprio paciente, para feridas da córnea tem mantido uma alta taxa de sucesso para preservar tanto a visão quanto a integridade do globo ocular [4,8]. O procedimento cirúrgico deste relato apoia-se nessa informação, pois o reparo tecidual da córnea se deu com a necessidade coadjuvante de tecido autólogo da membrana de terceira pálpebra, que propiciou boa contenção da perfuração da córnea, evitando novos traumas externo. 
O tratamento para a descemetocele consiste em suturar a córnea sobre o defeito e colocar a terceira pálpebra ou flap conjuntival sobre a mesma, seguido do uso de antibioticos tópicos [10]. Essa indicação condiz com a que foi realizada no felino, levando ao êxito terapêutico e manutençao da integridade do olho. Pesquisas também citam o uso da cola de cianoacrilato no processo de cicatrização da úlcera perfurada, que além de recuperação da mesma, também previne a ceratite infecciosa ou aumento de pressão intraocular [2].

O recobrimento com a terceira pálpebra com a passagem do fio de seda através da membrana nictante, fixando o fio junto à pálpebra superior, fechando o ponto sobre um tubo de silicone como tratamento conjunto a ceratoplastia para correção de descemetocele já foi descrito em gatos [12]. Porém, no presente estudo, adotou-se o fio de poliglactina, uma vez que há relatos na literatura de reações alérgicas ao fio de seda, empregado em diversas cirurgias oftálmicas [5].

Complicações graves após intervenções cirúrgicas do tratamento da membrana de descemet com perfuração da córnea podem ocorrer, e as taxas de sucesso relatados por alguns pesquisadores, foram longe do ideal, quando se utilizou por exemplo, membranas ricas em plaquetas e fibrina (PRF), associadas a terapia cirúrgica, sugerindo assim, que há a necessidade deadoção de um método alternativo com características superiores a tal técnica, adotada principalmente em humanos [1]. Durante o tratamento instituído na paciente felina, houve total sucesso do método utilizado e sem qualquer complicação pós-cirúrgica.

Casos em oftalmologia veterinária assumem um papel importante no atual contexto da clínica e cirurgia de pequenos animais, pois, viabiliza a troca de informação e atualização dos profissionais da área. O tratamento, com o emprego da técnica adequada utilizada no presente relato obteve sucesso terapêutico no, mantêve-se a estética e visão do felino.

\author{
MANUFACTURERS \\ ${ }^{1}$ Syntec do Brasil Ltda. Cotia, SP, Brazil. \\ ${ }^{2}$ Laboratório Cristália. São Paulo, SP, Brazil. \\ ${ }^{3}$ Fresenius Kabi Brasil Ltda. Aquiraz, CE, Brazil. \\ ${ }^{4}$ Novartis Biociências S.A. São Paulo, SP, Brazil. \\ ${ }^{5}$ Jhonson \& Jhonson do Brasil Ltda. São Paulo, SP, Brazil. \\ ${ }^{6}$ Virbac do Brasil. São Paulo, SP, Brazil. \\ ${ }^{7}$ Merial Saúde Animal Ltda. Campinas, SP, Brazil.
}

Declaration of interest. The authors report no conflicts of interest. The authors alone are responsible for the content and writing of the paper.

\section{REFERENCES}

1 Alio J.L., Rodriguez A.E., Martinez L.M. \& Rio A.L. 2013. Autologous fibrin membrane combined with solid plateletrich plasma in the management of perforated corneal ulcers: a pilot study. JAMA Ophthalmology. 131(6): 745-751.

2 Cavanaugh T.B. \& Gottsch J.D. 1991. Infectious keratitis and cyanoacrylate Adhesive. American Journal Ophthalmology. 111(4): 466-472.

3 Gelatt K.N. 2007. Ophthalmology. 4th edn. Philadelphia: Blackwell, 1672p.

4 Goulle F. 2012. Use of porcine small intestinal submucosa for corneal reconstruction in dogs and cats: 106 cases. Journal of Small Animal Practice. 53: 34-43.

5 Herrera D. 2008. Oftalmologia Clínica em Animais de Companhia. São Paulo: MedVet Livros, 316p.

6 Khokhar S., Natung T. \& Sony P. 2005. Amniotic membrane transplantation in refractory neurotrophic corneal ulcers: a randomized, controlled clinical trial. American Journal of Ophthalmology. 24(6): 654-660.

7 Krachmer J.H., Mannis M.J. \& Holland E.J. 2010. Management of Corneal Perforations. In: Marc A. \& Christopher J. (Eds). Cornea. 3rd edn. Davis: Mosby - Elsevier Health Sciences, 2080p.

8 Lewin G.A. 1999. Repair of a full thickness corneoscleral defect in a German shepherd dog using porcine small intestinal submucosa. Journal of Small Animal Practic. 40(7):340-342.

9 Solomon A., Meller D. \& Prabhasawat P. 2002. Amniotic membrane grafts for nontraumatic corneal perforations, descemetoceles, and deep ulcers. Ophthalmology. 109(4): 694-703.

10 Vanore M., Chahory S. \& Payen G. 2007. Surgical repair of deep melting ulcers with porcine small intestinal submucosa (SIS) graftin dogs and cats. Veterinary Ophthalmology. 10(2): 93-99.

11 Vygantas K.R. \& Whitley R.D. 2003. Management of deep corneal ulcers. Compendium on Continuing Education for the Practicing Veterinarian. 25(3): 196-205.

12 Walde I., Schäffer E.H. \& Köstlin R.G. 1998. Oftalmologia dos felinos. 2.ed. São Paulo: Manole, 360p. 